\title{
An Aproximation to Solution of Space and Time Fractional Telegraph Equations by the Variational Iteration Method
}

\author{
Ji-Huan He \\ National Engineering Laboratory for Modern Silk, College of Textile and Engineering, Soochow University, \\ 199 Ren-ai Road, Suzhou 215123, China \\ Correspondence should be addressed to Ji-Huan He, hejihuan@suda.edu.cn
}

Received 23 August 2012; Accepted 1 September 2012

Copyright (C) 2012 Ji-Huan He. This is an open access article distributed under the Creative Commons Attribution License, which permits unrestricted use, distribution, and reproduction in any medium, provided the original work is properly cited.

Sevimlican suggested an effective algorithm for space and time fractional telegraph equations by the variational iteration method. This paper shows that algorithm can be updated by either variational iteration algorithm-II or the fractional variational iteration method.

As early as 1998, the variational iteration method was shown to be an effective tool for factional calculus [1]; afterwards, the method has been routinely used to solve various fractional differential equations for many years, see the review article in [2] for a detailed summarization. Sevimlican [3] also followed the solution given in [1]; however, the algorithm can be further improved.

Sevimlican considered the following one-dimensional space fractional telegraph equation:

$$
\frac{\partial^{\alpha} u}{\partial x^{\alpha}}=\frac{\partial^{2} u}{\partial t^{2}}+\frac{\partial u}{\partial t}+u, \quad 1<\alpha<2
$$

and obtained the following iteration formulation:

$$
u_{n+1}(x, t)=u_{n}(x, t)+\int_{0}^{x}(s-x)\left\{\frac{\partial^{\alpha} u_{n}(s, t)}{\partial s^{\alpha}}-\frac{\partial^{2} u_{n}(s, t)}{\partial s^{2}}-\frac{\partial u_{n}(s, t)}{\partial s}-u_{n}(s, t)\right\} d s
$$


We can also construct a correction functional in the form

$$
u_{n+1}(x, t)=u_{n}(x, t)+\int_{0}^{x} \lambda\left\{\frac{\partial^{\alpha} \tilde{u}_{n}(s, t)}{\partial s^{\alpha}}-\frac{\partial^{2} u_{n}(s, t)}{\partial s^{2}}-\frac{\partial \tilde{u}_{n}(s, t)}{\partial s}-\tilde{u}_{n}(s, t)\right\} d s .
$$

If the multiplier $\lambda$ can be exactly identified, then one iteration results in the exact solution; however, the exact identification of the multiplier is impossible for most problems, and an approximate identification is always followed. To this end, $\tilde{u}_{n}$ in (3) is assumed to be a known function, and it is generally called a restricted variable [4]. After identification of the multiplier, we obtain the following variational iteration Algorithm-II [5]:

$$
u_{n+1}(x, t)=u_{0}(x, t)-\int_{0}^{x}(s-x)\left\{\frac{\partial^{\alpha} u_{n}(s, t)}{\partial s^{\alpha}}-\frac{\partial u_{n}(s, t)}{\partial s}-u_{n}(s, t)\right\} d s
$$

If we begin with $u_{0}(x, t)=u_{0}(0, t)+x u_{x}(0, t),(4)$ leads to the same result as given in [3].

The fractional variational iteration method is also suitable for the present problem, see the solution process in [5-7].

\section{Acknowledgment}

The work is a project funded by PAPD (The Priority Academic Program Development of Jiangsu Higher Education Institutions).

\section{References}

[1] J.-H. He, "Approximate analytical solution for seepage flow with fractional derivatives in porous media," Computer Methods in Applied Mechanics and Engineering, vol. 167, no. 1-2, pp. 57-68, 1998.

[2] J. H. He, "Asymptotic methods for solitary solutions and compactons," Abstract and Applied Analysis. In press.

[3] A. Sevimlican, "An approximation to solution of space and time fractional telegraph equations by He's variational iteration method," Mathematical Problems in Engineering, vol. 2010, Article ID 290631, 10 pages, 2010.

[4] J.-H. He, "Some asymptotic methods for strongly nonlinear equations," International Journal of Modern Physics B, vol. 20, no. 10, pp. 1141-1199, 2006.

[5] J.-H. He, "A short remark on fractional variational iteration method," Physics Letters A, vol. 375, no. 38, pp. 3362-3364, 2011.

[6] G.-C. Wu, "A fractional variational iteration method for solving fractional nonlinear differential equations," Computers E Mathematics with Applications, vol. 61, no. 8, pp. 2186-2190, 2011.

[7] G.-C. Wu and E. W. M. Lee, "Fractional variational iteration method and its application," Physics Letters A, vol. 374, no. 25, pp. 2506-2509, 2010. 


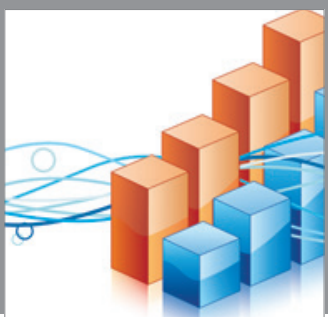

Advances in

Operations Research

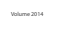

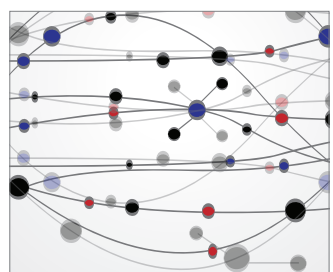

\section{The Scientific} World Journal
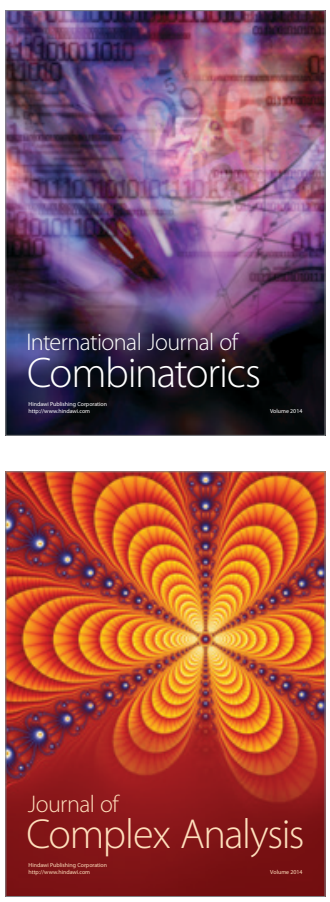

International Journal of

Mathematics and

Mathematical

Sciences
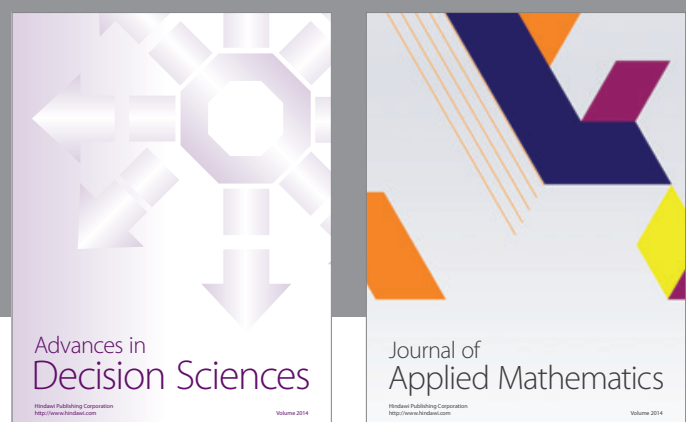

Journal of

Applied Mathematics
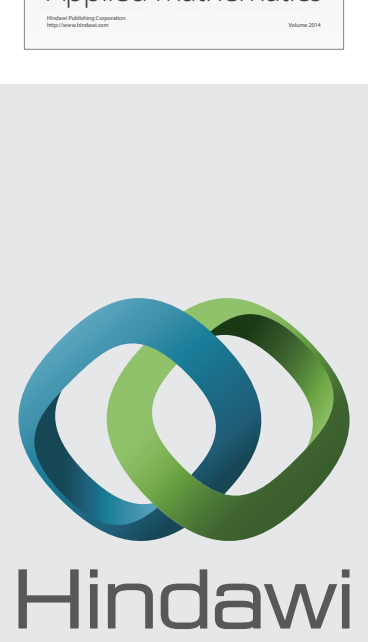

Submit your manuscripts at http://www.hindawi.com
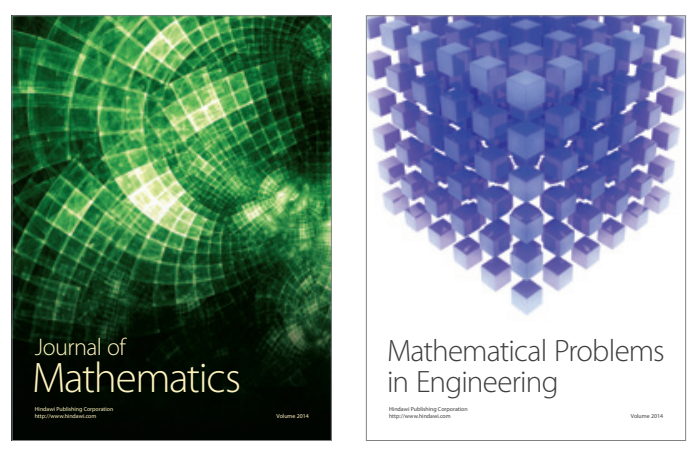

Mathematical Problems in Engineering
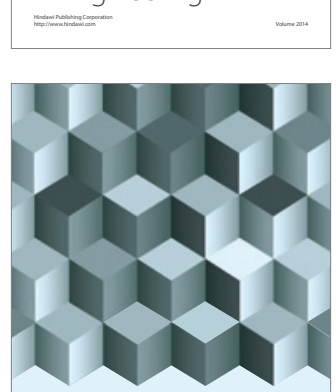

Journal of

Function Spaces
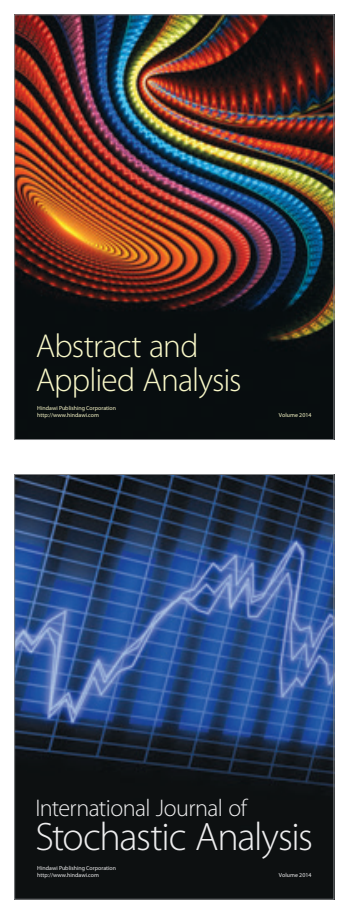

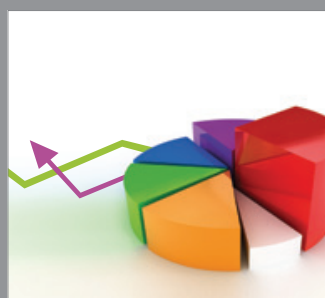

ournal of

Probability and Statistics

Promensencen
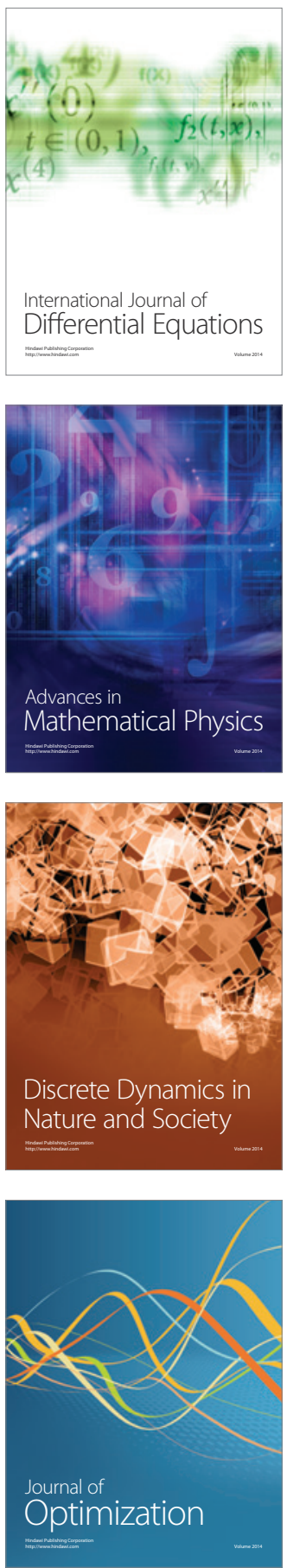